\title{
Alberto G. Ibáñez: La guerra cultural. Los enemigos internos de España y Occidente. Almuzara, 2020, $419 \mathrm{pp}$.
}

\section{Santiago González-Varas (Universidad de Alicante)}

\section{Resumen}

El libro que comentamos se adentra en el proceloso mundo, muy de moda, de la "guerra cultural" (contra España y Occidente), pero lo hace de forma innovadora y hasta provocativa. No sólo en cuanto a su metodología multinivel, sino por un enfoque "relacional-integral" que trata de salir del "bloqueo intelectual" en el que nos mantienen "pares de contradicciones" en apariencia irresolubles. Por otra parte, su apuesta por detectar cuáles son nuestros "enemigos internos" lo aleja de cualquier tentación victimista. No niega que existan agentes externos que esperan beneficiarse de la caída de España y Occidente, pero el autor resalta que la mayor amenaza viene de dentro, siendo ésta la más peligrosa pues suele pasar desapercibida. Lo mejor del libro es que nos hace pensar y que es difícil acabar su lectura sin haber cambiado en algo lo que pensábamos cuando lo empezamos.

Palabras clave: guerra cultural, enemigos internos, Occidente, España

El término "guerra cultural" parece que ha pasado a formar parte del paisaje intelectual y mediático, si bien normalmente tras su uso suele haber poco más que algunas frases hechas o unos planteamientos vagos que la relacionan con la (nueva) guerra híbrida de las fake news. Resulta difícil encontrar aportaciones novedosas en este campo. Pues bien, el libro que comentamos es una "rara avis" que no sólo se detiene en profundizar en el concepto de guerra cultural, sino que va mucho más allá, hasta el punto de que resulta difícil de calificar. Parte de la definición de "cultura" como "el conjunto de valores, principios, creencias o sobreentendidos que permean, dirigen o sustentan implícita o explícitamente el funcionamiento de una sociedad". Esta definición puede sorprender a algunos, pero, como el autor muestra, entronca con las concepciones de grandes pensadores, comenzando por el fundador de la antropología académica, Edward Burnett Tylor, y pasando por C.S. Coon o M. Harris. 
A partir de aquí el libro plantea la tesis de que la cultura-raíz que ha venido sirviendo de fundamento a Occidente y a España está en peligro de disolución sin que se vea una alternativa que la mejore o que nos fortalezca como sociedad. Y ello no solo por sus adversarios externos, sino principalmente por sus enemigos internos, los más peligrosos de todos porque uno nunca está preparado para la puñalada por la espalda del que cree ser su amigo, familiar o compatriota. En este sentido, el autor se aprovecha de su experiencia en los análisis (históricos) llevados a cabo en sus libros La Conjura silenciada contra España y La Leyenda Negra: Historia del odio a España, donde ya diferenciaba entre "hispanófobos" (adversarios externos) e "hispanobobos" (quintacolumnistas internos). De hecho, la leyenda negra hispanófoba es uno de los primeros casos constatados de guerra cultural organizada y mantenida en el tiempo no solo contra un país y su historia, sino contra el cuadro de valores, creencias y costumbres que le habían llevado en amenazar con convertirse en "monarquía universal", como destacara Tomas Campanella. Al final del libro volverá sobre esta cuestión.

El libro lleva a cabo un estudio sociológico, psicológico, político, económico y filosófico de la crisis del mundo occidental y español. Por tanto, se trata un análisis interdisciplinar, lo que siempre constituye un reto ambicioso que corre el peligro de perderse o defraudar. En este caso, el autor logra conducir el barco a buen puerto gracias a una innovadora técnica metodológica que da coherencia y unidad al ensayo. De hecho, algunas de las aportaciones más interesantes del libro se sitúan al principio, donde se concreta qué cabe entender por Occidente, cuál es su origen y, en consecuencia, cómo la crisis española y occidental están intrínsecamente relacionadas: si España se encuentra al origen de muchos aspectos de lo que todavía entendemos hoy por Occidente, resulta lógico pensar que si cae aquélla caiga éste.

El método que aplica a su diagnóstico y análisis se resume en un modelo con cuatro niveles. En primer lugar, un enfoque transversal, pues todo fenómeno complejo debe abordarse superando trincheras ideológicas, la doble vara de medir, los prejuicios sectarios, el apego al "cliché" o la "política de un solo ojo". En segundo lugar, el autor considera que el debate actual está enquistado en un "bloqueo ideológico" al venir presidido por "pares opuestos" que forman un pantano de contradicciones, una dualidad mutuamente excluyente que se retroalimenta hasta el infinito en una sucesión interminable de tesis y antítesis que ya no buscan ninguna síntesis. Este virus cultural contamina la sociedad y la lleva a una polarización extrema. Para hacer frente a esta cuestión el autor nos propone un método relacional-integral, que no se limita a relacionar horizontalmente elementos aparentemente contradictorios y paradójicos, sino que trata de integrarlos verticalmente para "subir de nivel", método que el autor ya aplicó, con éxito, en una de sus dos tesis doctorales: Mal, Religión y Saber: una lucha relacional-integral frente a una realidad ambivalente (2011). 
Cada capítulo y apartados principales comienzan identificando el par de contradicciones que bloquea el debate en cada particular cuestión, y termina, tras valorarlas, proponiendo una conclusión "relacional-integral" que relaciona e integra opuestos. Para llegar a esa conclusión, en tercer lugar, el ensayo utiliza un enfoque "retrocausal": partiendo de que todo fenómeno complejo es multicausal, por lo que debe ser analizado desde más de un punto de vista, buscando la causa de la causa (la causa del mal causado), la causa/realidad implícita o subyacente que se encuentra tras la causa/realidad aparente (cfr. David Bohm), huyendo así de los peligros del single-cause approach ya que toda "toda explicación que parezca simple y lógica resulta inevitablemente errónea" (cfr. A. Daniélou).

La obra por su enfoque y objeto (presente y futuro de la civilización occidental) recuerda a las obras de S. Pinker y a Y.H. Harari, a los que cita. Como en estas obras el análisis teórico se apoya en numerosos datos de fuentes públicas y oficiales, así como en cuarenta y nueve casos reales (que aparecen numerados) extraídos de los medios de comunicación, la experiencia personal o el testimonio validado de terceros. De esta manera, se logra combinar el enfoque macro/teórico (las ideas) con el micro/práctico: "los hechos que acaecen cada día, la historia de las anécdotas" de la que hablaba Mérimée, pues para estudiar algo tan complejo como la cultura se requiere adoptar una metodología necesariamente impresionista por la imposibilidad absoluta de cubrir todos los frentes.

Por último, el círculo metodológico del libro se cierra con dos "ideasfuerza" que se proyectan en todos los capítulos: una "constante argenta" que se aplicaría a todos los fenómenos sociales (20/60/20) y el principio de que "no hay ética sin límites" (nulla ethica sine finibus). No podemos profundizar en esta breve reseña en el contenido de estos dos interesantes planteamientos, pero especialmente novedosa resulta la idea de que existe una constante "argenta" (por el paralelismo con la proporción "áurea") que rige la sociedad, la cual, como ocurre con la naturaleza, estaría sometida a algunas leyes. Es una vieja, y normalmente frustrada, ambición encontrar las leyes sociales, pero en este caso la propuesta resulta convincente al basarse tanto en estudios psicológicos como sociológicos, incluido el principio de Pareto. "Nada se da al 100\%", nos recuera el autor, pues siempre existe como mínimo un $20 \%$ que se resiste al cambio o a la uniformidad, eso sí tanto para bien como para mal. En segundo lugar, el objetivo de encontrar un nuevo equilibrio exige concretar los límites que pongan coto a los variados excesos en que hemos caído tanto a nivel individual y colectivo. Este afán por encontrar el camino del medio y la huida de los excesos nos recuerda a Lou Marinoff, The Middle Way: ABC's of Happiness in a World of Extremes, obra con la que cabe encontrar más de un paralelismo. 
Por otra parte, en cuanto al contenido más en concreto, el autor recuerda que las grandes batallas se empiezan perdiendo en casa, lo que le lleva a apostar por el análisis de los distintos enemigos internos de Occidente (parte I) y España (parte II). La selección de estos "enemigos" puede resultar cuestionable, y cada cual echar de menos a alguno. El propio autor reconoce que toda selección es necesariamente incompleta, pero que si "no están todos los que son", al menos asegura que "son todos los que están". Y en esto también podemos estar de acuerdo. A los enemigos internos de Occidente se dedican cuatro capítulos: el proceso de deconstrucción del individuo y de la realidad (capítulo II), la creciente fragmentación política y social (capítulo III), el lado oscuro de la innovación y la tecnología (capítulo IV), así como una crisis económica que amenaza con convertirse en permanente (capítulo V). Todos ellos se subdividen en varios apartados (más enemigos potenciales) aportando análisis de interés difíciles de resumir. Como triple conclusión de esta parte podría resaltarse que no somos tan racionales como pensamos, ya que no sabemos por qué pensamos lo que pensamos; que la edad de la información masiva ha producido paradójicamente la edad del aturdimiento, la confusión y el pensamiento superficial; y que la postmodernidad, que venía de la izquierda, ha servido igualmente de forma paradójica para consolidar el capitalismo de casino.

En cuanto a España, el autor considera que la hidra occidental se mueve de forma similar a otros países occidentales, pero que en nuestro caso el virus cultural adopta patologías específicas que lo convierten en más radical y peligroso. En concreto, los principales enemigos internos de España se agruparían en torno a los siguientes elementos: el virus de la ingenuidad, división, complejos y obsesiones (capítulo VI); los excesos de una España pendular (capítulo VII); el fracaso de nuestro modelo educativo (capítulo VIII), una ciclogénesis explosiva que pone en peligro la supervivencia del régimen del 78 (capítulo IX) y una operación orquestada, desde dentro y desde fuera, para romper España y acabar con la nación que nos ha unido desde hace siglos (capítulo X). Resulta difícil de nuevo resumir todas las observaciones que se hacen en esta parte, pero sin duda resultan especialmente interesantes las reflexiones dedicadas al caso "singular" del modelo educativo español, donde los cambios que se introdujeron a partir de la transición han llevado paradójicamente a los peores resultados de la OCDE sin que se reduzca paralelamente la desigualdad entre regiones (siendo de esta manera su mayor fracaso), lo que se achaca a un error de diagnóstico. Del mismo modo, resulta destacable el enfoque sobre el fenómeno del separatismo, que para el autor tendría una raíz más de tipo cultural que de conflicto históricopolítico.

Pero el libro no solo ofrece conclusiones relacionales-integrales que ayudan a salir del bloqueo de pares contrapuestos. También acaba con un último capítulo donde se propone un "nuevo renacimiento cultural" necesario tanto 
para Occidente como para España. Para ganar el futuro no podemos despreciar lo mejor de nuestro pasado, sino en su caso actualizarlo. Si cortamos las raíces de un árbol (filosofía griega, derecho romano, escolástica, ilustración y humanismo cristiano) éste se secará sin remedio; mejor concentrarse en la poda y tal vez experimentar con algún injerto. Como dicen los franceses: "reculer pour mieux sauter". De especial interés en este sentido resulta la propuesta, bastante detallada, de recuperar un modelo cultural de éxito olvidado: el de la América virreinal que se fundamentaba, entre otros aspectos, en la base conceptual de la Escuela de Salamanca, que cubría el derecho y el funcionamiento de la economía y el mercado, enmarcado todo ello en la doctrina social de la Iglesia (creada por esa misma Escuela). Mientras funcionó dicho modelo América tuvo éxito en todos los órdenes; cuando tras la independencia se decidió acabar con él llegó la decadencia.

En todo caso, el libro podría haber tenido incluso un título más provocativo, como La dictadura cultural, pues esta idea late en algunos párrafos del libro. Tal vez el autor no se haya atrevido a tanto por su afán de huir de los extremos y no querer ser encuadrado en una corriente ideológica concreta, pero podría haber echado mano a este respecto del libro de Michel Onfray Théorie de la dictature précedé de Orwell et l'Empire maastrichien (2019). Si bien, probablemente, no tuvo ocasión de leerla, ya que el manuscrito, aunque publicado en octubre de 2020, se entregó en marzo de ese año como se explica en el Prefacio: "Enseñanzas de este libro para un mundo post-pandemia".

Del mismo modo, dado que el ensayo trata del cambio cultural que estamos viviendo, se echa en falta el análisis de la obra de Gramsci, entre otros marxistas europeos, que explican cómo se lleva a cabo el proceso de cambio de una sociedad dada a partir del dominio de las instituciones culturales. U otras obras de procesos de ingeniería social como la de Kevin D. Mitnick, el maestro de hackers, que en su libro The art of deception nos alerta que mientras los hackers normales atacan máquinas, los profesionales se dedican a hackear personas. De hecho, en psicología cognitiva se habla del "sesgo ciego", que se aplica a las personas que se creen que no tienen sesgo, en el fondo los más fáciles de ser manipuladas.

No obstante, estas ausencias cabe justificarlas, como el autor llega a dar a entender, por la necesidad de poner límites a una obra que corría el riesgo de ser excesivamente ambiciosa y resultar demasiado extensa. El resultado de 419 páginas, 220 fuentes bibliográficas, y un centenar de artículos citados a lo largo de las 144 notas a pie de página muestran que, como en el caso de la ética, "no hay buen libro sin límites", y que aunque no están (ni pueden estar) citados todos los autores que son, los que aparecen mencionados bastan y sobran para dar una adecuada cobertura teórica al ensayo 
Por último, más allá de que se pueda compartir o no todo lo que dice el autor (según su propia tesis resultaría imposible coincidir en más del 80\%), nos encontramos sin duda ante una de las obras claves para entender lo que está ocurriendo en España y Occidente y plantear cómo, a partir de un correcto y equilibrado diagnóstico, se puede salir de esa telaraña oscura que nos envuelve. Como dice el autor, "hay redes que salvan, pero otras que apresan". De hecho, A.G. Ibáñez podría con esta obra, con sobrados merecimientos, pasar por el "Harari español", pero mucho nos tememos que no goce de similar reconocimiento público y académico, ya que en estas tierras españolas se tiene a gala con demasiada frecuencia probar con hechos contantes y sonantes el famoso aforismo de que "nadie es profeta en su tierra", así como de blandir orgullosos e ingenuos el lema de que "inventen ellos". Si alguien logra superar estas dos tentaciones, le recomiendo vivamente la lectura del libro que comentamos.

\section{Bibliografía:}

G. Ibáñez, Alberto (2011) Mal, Religión y Saber: una lucha relacional-integral frente a una realidad ambivalente (Tesis doctoral presentada en el Instituto Interuniversitario de Ciencias de las Religiones, UCM, Madrid)

G. Ibáñez,Alberto(2016), La conjura silenciada contra España: la manipulación franco-anglosajona de nuestra historia y sus quintacolumnistas ingenuos, ed. M\&2, Madrid

G. Ibáñez, Alberto (2018), La Leyenda negra: historia del odio a España. Ed. Almuzara, Córdoba,

Marinoff, Lou (2020), The Middle Way: ABC's of Happiness in a World of Extremes, ed. Ed. Waterside, Cardiff

Onfray, Michel (2019), Théorie de la dictature précedé de Orwell et l'Empire maastrichien, ed. Robert Laffont, Paris

Mitnick, Kevin D \& Simon, William L. (2002), The art of deception. Controlling the Human Element of Security, ed. John Wiley \& Sons, New Jersey 